\title{
Igualdad de oportunidades *
}

\author{
JOHN E. ROEMER ** \\ Departamento de Economía \\ Universidad de California, Davis
}

El autor explora en este artículo dos concepciones de la igualdad de oportunidades ampliamente difundidas en las democracias occidentales de nuestros días. Al clásico principio del mérito opone la igualdad de oportunidades en la adquisición del mérito, que discute apoyándose en la metáfora de la nivelación del terreno de juego. Roemer propone un modelo matemático elemental para analizar el peso del esfuerzo y las circunstancias individuales en la formación individual y, de acuerdo con éste, desarrolla un algoritmo para evaluar la inversión estatal en los programas de igualación de oportunidades. Este algoritmo se ilustra con su aplicación en dos casos (sanitario y educativo, respectivamente) y se acompaña de una discusión de las dificultades que aparecen en su desarrollo.

Dos concepciones de la igualdad de oportunidades prevalecen hoy en las democracias occidentales. La primera establece que la sociedad debicra hacer lo posible para "nivelar el terreno de juego" entre los individuos que compiten por un puesto, o nivelarlo previamente durante su período de formación, de modo que todos aquellos capaces de desempeñarlo sean aceptados, llegado el caso, entre los aspirantes que van a competir por él. La segunda concepción, que denomino «principio de no discriminación o de mérito», establece que en la competencia por un puesto en la sociedad han de ser incluidos entre los aspirantes todos aquellos que poseen las características adecuadas para desempeñar las obligaciones que dicho puesto conlleva, y a la vez que su elección para éste se decidirá atendiendo solamente a estas características. Un ejemplo del primer principio es proporcionar una educación compensatoria a los niños de medios sociales desfavorecidos, de modo que un mayor número de ellos adquiera la cualificación necesaria para después competir por un empleo con niños de extracción más favorecida. Un ejemplo del segundo principio es que la raza o el sexo como tales no debieran contar en favor o en contra de la

* Traducción de David Teira Scrrano.

** Este trabajo fue presentado como contribución al III Simposjo sobre igualdad y distribución de la renta, organizado por la Fundación Argentaria, Madrid 15 al 19 de diciembre de 1997. Agradecemos a là Fundación Argentaria su amable autorización para esta publicación. 
elección de una persona para un puesto, cuando éstas sean características irrelevantes en lo que al desempeño de sus funciones se refiere.

La aplicación del principio de nivelación del terreno de juego tiene mayor alcance que la del principio de no discriminación. Puede, por ejemplo, establecer que la igualdad de oportunidades exija la igualación del gasto educativo por alumno en una región o un país. De no llevarse a cabo tal igualación, la no discriminación en la competencia por un empleo no garantizaría por sí sola la igualdad de oportunidades, pues si los niños de distritos ricos hubiesen tenido acceso a una mejor educación en sus escuelas que los niños de distritos pobres, el terreno de juego no habría estado nivelado. En realidad, en tal caso, la igualdad de la inversión escolar por alumno puede que no nivele demasiado el terreno de juego. Si un niño educado es el resultado de la aplicación de cierta tecnología a un paquete de recursos, de los cuales algunos están más allá de la influencia de las escuelas - los genes del niño, su familia, su vecindario - y otros pueden, en cambio, ser aportados por la autoridad educativa competente - profesores, escuelas, libros--, cabría pensar que la nivelación del terreno de juego exige compensar a quienes tengan una dotación menor de aquellos recursos con una dosis complementaria de estos últimos.

Entre la ciudadanía de cualquier democracia avanzada, encontramos individuos con opiniones muy diversas sobre lo que es necesario para la igualdad de oportunidades, desde la concepción no discriminatoria, en un extremo, hasta la intervención social para corregir todo género de desigualdades, en el otro. En cualquier caso, es común a todas ellas el precepto de que el principio de igualdad de oportunidades exige en algún momento que el individuo se haga responsable de la consecución de tal igualdad, bien se refiera ésta a una determinada cualificación escolar, salud, nivel de empleo o salario, o a la utilidad o bienestar del economista. Por tanto, hay un «antes» y un «después» en el concepto de igualdad de oportunidades: antes de que comience la competición deben igualarse las oportunidades, incluso mediante una intervención social, si es necesario; pero una vez que comienza, los individuos han de asumir plenamente su responsabilidad. Pueden clasificarse las distintas concepciones de la igualdad de oportunidades de acuerdo con el lugar en el que sitúen el umbral a partir del cual los individuos asumen esta responsabilidad.

En este trabajo intentaré establecer con exactitud cómo debiera nivelarse el terreno de juego, una vez decidida la ubicación de este umbral. Propondré después un algoritmo que posibilitará a la sociedad (a un planificador social) la traducción de cualquier concepción acerca de la ubicación de este umbral en una política social que desarrollará un grado de igualdad de oportunidades acorde con ella. Si se acepta mi algoritmo, por considerarlo razonable, el debate político general sobre la igualdad de oportunidades se podría transformar en otro más refinado acerca del auténtico ámbito de la responsabilidad individual. Una vez consensuado este ámbito, resulta que de la aplicación del algoritmo que propongo se seguirá más o menos automáticamente una política de igualdad de oportunidades bien definida. 
Quede, pues, dicho que mi propósito es pluralista, en el sentido de que ofrezco un instrumento que puede ser empleado para calcular una política de igualdad de oportunidades acorde con cualquier concepción de la responsabilidad individual. Es también pluralista en otro sentido. Gente con una concepción muy distinta de la justicia distributiva apoya la igualdad de oportunidades. No intento abogar por una concepción particular de la justicia distributiva. Defensores de muy diversas teorías de la justicia distributiva abogan por la igualdad de oportunidades no sólo en distintos grados (esto es, con diferentes concepciones de la responsabilidad), sino también en distintos dominios de la vida social. Desearía que personas provenientes de muy diversos puntos del espectro político pudiesen emplear mi propuesta sin que por ello se vean obligados a defender un igualitarismo más general que el que ya aceptan.

Puesto que el principio de no discriminación es bien conocido, me ocuparé aquí de articular cuidadosamente la concepción «niveladora del terreno de juego» de la igualdad de oportunidades.

Por seguir con la metáfora del terreno de juego, iqué corresponde en la formación del individuo a los socavones que debieran nivelarse? Propongo que sean aquellas circunstancias diferenciales de los individuos de las que no les creamos responsables, y que afecten a su capacidad para alcanzar o tener acceso a la ventaja que buscan. Consideremos, concretamente, el acceso a la vida buena que facilita la educación. Nuestra sociedad considera la educación como un aporte de tanta importancia en la vida buena que percibe de forma imperativa el proporcionar una educación decente a todo individuo. En realidad, garantizar la igualdad de oportunidades aparentemente requeriria proporcionar igual cantidad de recursos educativos a todo individuo, y este objetivo ha sido alcanzado, en distintos grados, en diferentes países y regiones. Históricamente en Estados Unidos los ayuntamientos han financiado la educación, y esto ha producido escuelas desiguales en municipios con desiguales niveles de renta. En California hay una ley que le exige al Estado subvencionar las escuelas municipales, de modo que el gasto por cada estudiante sea igual en ese Estado. El caso Brown (juzgado en el Tribunal Supremo en 1954) estableció que la igualdad educativa entre blancos y negros exigía la integración escolar: la política anterior de «separados pero iguales» se juzgó contradictoria. A causa de la existencia de colegios privados no se igualarían los recursos totales dedicados a la educación, incluso en el caso de que en los Estados Unidos se igualara el presupuesto per cápita. Problema que no se da en los países nórdicos porque allí no existe prácticamente escuela privada.

Garantizar igual financiación educativa per cápita no es suficiente, en cualquier caso, para obtener idénticos resultados escolares, ya que cada nin̄o es capaz de usar los recursos educativos (profesores, libros, instalaciones) con 
diferentes grados de efectividad o eficiencia. Considerando un caso extremo, los niños con un retraso mental requieren muchos más recursos que los niños normales para alcanzar un rendimiento similar, o al menos un nivel que entendamos aceptable. Que proveamos más recursos educativos para estos niños indica que no pensamos que la igualdad de oportunidades para la consecución de una vida buena, en tanto que la educación sea importante para ello, se logre mediante la igualdad de recursos educativos per cápita: creemos que debieran dedicarse más recursos a cierto tipo de niños si son incapaces de aprovecharlos con la misma efectividad que otros. iMas cuándo son incapaces de aprovechar estos recursos con igual efectividad y cuándo, siendo capaces de hacerlo, no lo hacen por propia elección?

Debemos distinguir entre las circunstancias que están más allá del control del nin̄o e influyen en su capacidad para aprovechar los recursos educativos, y sus actos autónomos de volición y esfuerzo. Suponiendo que esta capacidad esté determinada por circunstancias más allá del control del individuo, igualar las oportunidades para una vida buena, en la medida en que la educación sca uno de sus aportes $\rightarrow$, más precisamente, igualar las oportunidades de aprovechamiento escolar--, requiere distribuir los recursos educativos de manera que se compense la menor capacidad de los niños para transformar estos recursos en resultados escolares. Una política de igualdad de oportunidades no tendría que compensar o nivelar resultados diferenciales debidos a diferencias de esfuerzo o volición.

Por tanto, defino la capacidad de un niño para transformar recursos en resultados escolares como su propensión a efectuar esta transformación en virtud de circunstancias que están más allá de su control, entre las que contaríamos - por el momento- sus genes, sus antecedentes familiares, su cultura, y en general, su medio social. Pero dos niños en las mismas circunstancias, y por tanto con la misma capacidad, pueden alcanzar resultados educativos diferentes en virtud de su esfuerzo. Una concepción radical es la de que las circunstancias lo determinan todo, de modo que no hay lugar para un esfuerzo autónomo: si esto fuera cicrto, entonces diríamos que lo que aparentemente es fruto de diferentes esfuerzos está en realidad plenamente determinado por circunstancias diferentes. Esta posición, llamémosla determinismo, es sólo una posibilidad metafísica. El caso más general es que los resultados escolares vengan determinados conjuntamente por las circunstancias y el esfuerzo libremente elegido. Por ello, en la medida en que afecten a los resultados escolares, la igualdad de oportunidades exige compensar las diferentes circunstancias de las personas y no que se las compense por las consecuencias que resultan de las diferencias en su esfuerzo. Esta segunda concepción la apoya una gran mayoría, porque suponen que existe el esfuerzo libremente elegido.

Supongamos - algo difícil- que supiésemos exactamente qué circunstancias determinan la capacidad de un niño para transformar los recursos educativos en resultados escolares. Supongamos además que las circunstancias de un niño 
se pudiesen caracterizar como el valor de cierto vector de, digamos, $n$ componentes. Supongamos, por simplificar, que este vector toma un número pequeño (finito) de valores en la población infantil, considerablemente menor que el número de individuos. Entonces podríamos clasificar esta población en una clase de tipos, donde un tipo comprendería todos aquellos individuos para los cuales el valor del vector es aproximadamente el mismo. Por la propia definición de capacidad y tipo, todos los individuos de un tipo tendrían la misma capacidad para transformar recursos en resultados escolares. Por hipótesis, hay por término medio un número bastante amplio de individuos entre tipo y tipo, puesto que el número de tipos es pequeño comparado con el número de individuos. Supongamos además que hay un gran nümero de individuos en cada tipo.

Elaboraré la política de igualdad de oportunidades como sigue. Consideremos una distribución de recursos educativos tal que, cn cada tipo, cada individuo reciba la misma cantidad de recursos. (En general, habrá diferentes cantidades de recursos per cápita para los diferentes tipos.) Observaremos, con toda probabilidad, una distribución de niveles de esfuerzo en cada tipo, cada uno de los cuales conduciría a diferentes resultados escolares dentro de cada tipo. (Asumo aquí que el esfuerzo es unidimonsional y medible.) Adviértase que esta distribución de esfuerzo es en sí misma una característica del tipo, no de individuo alguno. La posíción concreta de un individuo en cada distribución se debe a su clección de esforzarse en uno u otro grado, puesto que, por construcción, los individuos del mismo tipo son idénticos respecto a sus circunstancias.

Propongo que la política de igualdad de oportunidades debe igualar por término medio los resultados escolares de todos los tipos, pero no los resultados de los individuos en cada tipo, que diferirán de acuerdo al esfucrzo. Por tanto, la igualdad de oportunidades exige que se compense a los individuos por las diferencias en sus circunstancias, pero no por las difcrencias en su esfuerzo, supuesto que la capacidad (consecuencia de las circunstancias) es fija.

Por definición, en el mundo, tal como lo he modelado, cualquier diferencia en los resultados, una vez definidos los tipos, se considera fruto de diferencias en el esfuerzo invertido o, como digo también, fruto de diferentes elecciones autónomas de los individuos. Considero autónomas las diferentes elecciones de individuos de un tipo en el sentido de que no se explican por las circunstancias (puesto que las circunstancias son las mismas en cada tipo). No está claro, en cualquier caso, cómo comparar las diferencias de esfuerzo entre individuos de diferentes tipos: pues esas diferencias de esfuerzo se deben en parte a que las distribuciones de esfuerzo son diferentes entre tipos.

No tengo una teoría con la que determinar cxactamente qué aspectos del medio de una persona están más allá de su control y afectan a un aspecto importante de su comportamiento de modo tal que resulte exonerada de su responsabilidad. En la práctica, la sociedad decidiría, mediante un proceso 
político, qué "circunstancias» desea estimar como ajenas a la responsabilidad individual. En este debate aflorarían desacuerdos de dos clases: el primero, concerniente a qué aspectos del comportamiento de una persona están realmente más allá de su control, y por tanto debieran atribuirse a las circunstancias, y el segundo respecto a la nivelación, total o parcial, del campo de juego. Volveré después sobre ambas cuestiones.

Analizando el caso educativo, propugnaría un conjunto de circunstancias que comprendiese el $\mathrm{Cl}$, los niveles de ingreso y educación de los padres, y la raza. Supongamos que la sociedad escoge este conjunto de circunstancias, que podría caracterizarse como un vector con tres componentes. La primera de ellas, el $\mathrm{CI}$, no se representaría mediante un valor continuo, sino quizá por cinco intervalos - de modo que pudiese tomar cinco valores-. De igual modo, cada componente podría tomar un número finito (aunque pequeño) de valores. Esto definiría un número finito de tipos, cada uno de los cuales comprendería, en un país con millones de niños, un gran número de individuos, suficientemente amplio como para hablar de distribuciones continuas de esfuerzo y resultados escolares en cada tipo.

La determinación del conjunto de circunstancias que caracterizaría al tipo sería polémica, puesto que se debatirían diferentes opiniones y teorías políticas, psicológicas, biológicas y sociales. En cualquier caso, la elección de este conjunto de circunstancias no vendría solamente determinada por tal diversidad de concepciones, sino también por las dificultades prácticas para recopilar la información necesaria. Muchos pueden coincidir, por ejemplo, en que el amor que sus padres le profesen puede ser una circunstancia que influya en la capacidad del niño para aprovechar los recursos educativos. En cualquier caso, no es posible, ni tampoco quizá conveniente, obtener esta información (por la invasión de la intimidad que ello supondría). Por tanto, las circunstancias debieran ser caractcrísticas individuales fácilmente observables y no manipulables.

Es evidente que habrá mâs tipos cuanto mayor sea el conjunto de circunstancias y más refinada nuestra medición de sus componentes. Debiéramos llegar a un acuerdo para no incrementar los tipos más allá de un número manejable.

¿En qué medida una política social debiera intentar igualar, por término medio, la consecución de determinada ventaja entre diferentes tipos? Consideremos el problema de distribuir los recursos educativos para igualar las oportunidades de poder ganarse la vida en un futuro entre los niños de un país. Una vez que, mediante un proceso político, se ha decidido la cuantía del presupuesto educativo, el problema al que se enfrenta el Ministerio de Educación, en mi modelo, es el de decidir cómo debiera distribuir el presupuesto entre los distintos tipos de niños. Imagínese una distribución concreta del presupuesto que asigne fondos escolares a cada tipo, de modo que todos los niños del mismo tipo disfruten de la misma cantidad, pero los gastos per cápita difieran en los diferentes tipos. De ello se seguirá una cierta distribución de 
esfuerzo en cada tipo: tomemos, por hipótesis, como medida del esfuerzo, el número de años que cada individuo ha asistido a la escuela.

Pues bien, como decía anteriormente, la distríbución de esfuerzo es una característica del tipo, no de un individuo. Que algunos tipos ofrezcan peores distribuciones de esfuerzo que otros se debe no a circunstancias individuales, sino a las circunstancias que caracterizan al tipo en cuestión. Puesto que un individuo no debiera ser penalizado por pertenecer a un tipo desfavorecido, sería equivocado medir su esfuerzo por su valor absoluto, ya que el valor medio del esfuerzo de algunos tipos, que es una característica de la distribución, estará muy por debajo del de otros. Creo que una buena medida para comparar el esfuerzo entre tipos es el centil de la distribución de esfuerzo de cada tipo en el que cada individuo se sitúe. Así, por ejemplo, dos individuos en el centil treinta de la distribución de esfuerzo de sus respectivos tipos habrán hecho el mismo esfuerzo.

¿Cuál es cl criterio que subyace a la elección de la distribución de esfuerzo como medida neutral intertípica? Al juzgar el esfuerzo de una persona, sólo sería justo compararlo con el de aquellas otras en circunstancias similares. Si hubiera un número pequeño de individuos en cada tipo, la elección del centil no sería tan convincente: pero con miles, o cientos de miles de individuos en cada tipo, cabe considerar su distribución de esfuerzo como un fenómeno natural. El centil nos ofrece entonces una medida aceptable del esfuerzo de cada cual respecto al de otros individuos de su mismo tipo. Pero en tanto que es una medida enteramente relativa (esto es, no definida en términos de unidades absolutas de esfuerzo), lo es también del esfuerzo relativo intertípico.

El objetivo de una política de igualdad de oportunidades es asignar recursos de modo que los resultados que una persona obtenga se correspondan solamente con su esfuerzo y no con sus circunstancias. Puesto que hemos propuesto como criterio de comparación intertípica del esfuerzo el centil de su distribución, la política que propongo es aquella que ofrezca resultados —en este caso, la capacidad para ganarse la vida en un futuro- $\tan$ iguales como sea posible entre aquellos individuos de distintos tipos situados en un mismo centil de sus respectivas distribuciones de esfuerzos. En cualquier caso, entre los individuos de cada tipo se pueden dar grandes diferencias respecto a su capacidad de ganarse la vida según varie su esfuerzo ${ }^{1}$.

'El algoritmo matemático exacto para calcular una política de igualdad de oportunidades se analiza más extensamente en mi libro Igualdad de oportunidades (Harvard University Press, 1998). 


\section{III}

Como ilustración de tal política de igualdad de oportunidades, aplicaré el algoritmo a un caso simple en cl cual el objetivo es igualar las oportunidades respecto a la esperanza de vida entre dos tipos que tienen diferentes riesgos sanitarios debido a sus distintas circunstancias y al esfuerzo invertido en el cuidado de su salud. Aquí el correspondiente esfuerzo se manifiesta en la calidad de la vida que uno lleva: quienes consumen una enorme cantidad de grasa, no hacen ejercicio y fuman obtienen un menor valor de esfuerzo. La distribución de esfuerzo en los dos tipos puede ser diferente. Hay una sola enfermedad mortal. La probabilidad de contraer la enfermedad es función a la vez del propio esfucrzo (esto es, de la calidad de vida) y de su tipo. Si uno contrae la enfermedad, la esperanza de vida será función entonces de lo invertido en su tratamiento. Socialmente, el problema es decidir, con un presupuesto dado, cuánto invertir por tipo en cada caso de la enfermedad para contrarrestar el efecto del tipo en la esperanza de vida, mas no el efecto de la calidad de vida del individuo.

Hay una enfermedad y dos tipos, cada uno de los cuales comprende la mitad de la población. El primer tipo vive con una calidad de vida cuyas cualidades estén uniformemente distribuidas en el intervalo $[0,1]$, mientras que la calidad de vida del segundo está distribuida en el intervalo $[0,5,1,5]$. La probabilidad de contraer la enfermedad, en función de la calidad de vida (e) y del tipo (1 6 o 2), resulta scr:

$$
\begin{aligned}
& p^{1}(e)=1-e / 2 \\
& p^{2}(e)=1-2 e / 3
\end{aligned}
$$

Por tanto, los individuos del primer tipo padecen una doble desventaja: la distribución de su calidad de vida es inferior a la de los individıos del scgundo típo $\mathrm{y}$, en cualquiera de los niveles de esta distribución, son más propensos a contraer la enfermedad que ćstos.

Supongamos que la esperanza de vida para cualquier individuo venga dada por;

60

si no se contrae la enfermedad.

$40+20(x-1) /(x+1) \quad$ si se contrae la enfermedad y $x$ es el gasto que supone su tratamiento.

Por tanto, si se contrae la enfermedad, la esperanza de vida estará entre 20 y 60 , dependiendo de cuánto se invierta en el tratamiento (desde cero a una cantidad infinita).

Como dccía anteriormente, consideraré la esperanza de vida como objetivo de la politica de igualdad de oportunidades. Supongamos que la sociedad haya dispuesto un presupuesto per cápita $x$ para tratar la enfermedad. El instrumento 
de esta política será la cantidad que se invierta en tratar cada caso de la enfermedad en uno $u$ otro tipo, un vector $\left(x_{1}, x_{2}\right)$.

Dados los datos anteriores, podemos hallar la distribución del presupuesto sanitario entre ambos tipos que, en dicha política, igualaría sus oportunidades respecto a la esperanza de vida. Primeramente, sea $\bar{x}=5$ (por ejemplo, digamos $5.000 \$$ per cápita). La solución de nuestra política es

$$
x_{1}=10,63 \quad x_{2}=6,08
$$

Esto es, invertiremos un 75 por 100 más en cada caso de la enfermedad contraída por el tipo desfavorecido que en los casos que se den en el tipo favorecido. La figura 1 muestra las esperanzas de vida de los dos tipos, expresadas en función del centil correspondiente a la calidad de vida en cada uno de ellos (el par de líneas finas). Las líneas gruesas en la figura 1 representan las expectativas de vida en los dos tipos, cuando en ambos se invierte una misma cantidad en cada caso que se da de la enfermedad. Por tanto, por ejemplo, la esperanza de vida varía de 56,5 a 57,5 años en el tipo desfavorecido, en el caso de una política de igualdad de oportunidades y de 56,1 a 57,4 si se destinase igual cantidad de recursos por caso en ambos tipos.

Figura 1.-Comparación de las dos soluciones

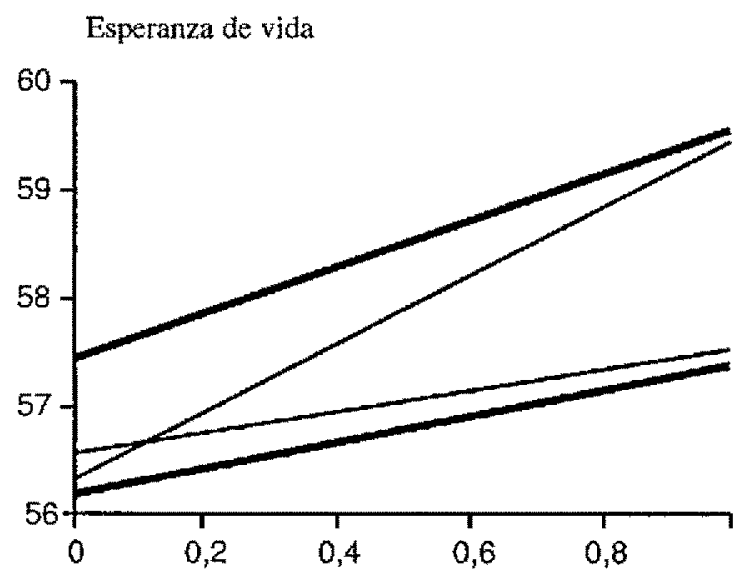

Las lineas finas representan la solución de la politica de igualdad de oportunidades. Las líneas gruesas, la solucion de la política de recursos.

Supongamos ahora que la sociedad incrementa el presupuesto sanitario en un 50 por 100 , hasta un 7,5 por 100 per cápita. Hallamos de nuevo el valor para nuestra política de igualdad de oportunidades, obteniendo esta vez:

$$
x_{1}=15,88 \quad x_{2}=9,27
$$


Gastaríamos alrededor de un 71 por 100 más en cada caso que se diese de la enfermedad en el tipo desfavorecido.

La figura 2 muestra los gráficos de la esperanza de vida en el caso de nuestra política de igualdad de oportunidades para un incremento presupuestario de un 5 por 100 per cápita (las líneas finas) y de un 7,5 por 100 per cápita (las líneas gruesas). Adviértase que a ambos tipos les va claramente mejor con un mayor presupuesto, y además éste permite una mayor igualdad de las funciones de esperanza de vida.

FIGURA 2. - La solución de la política de igualdad de oportunidades

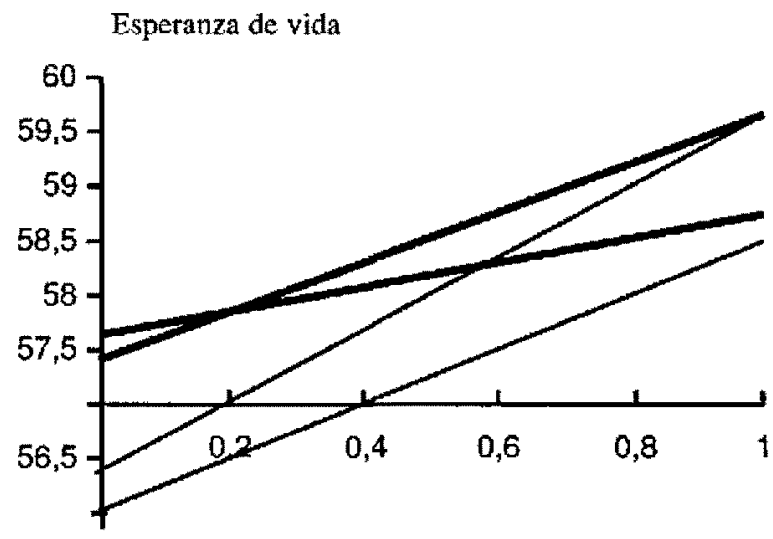

Las lineas finas corresponden a un incremento presupuestario del 5 por 100 per cópita. Las líneas gruesas a un aumento del 7,5 por 100 .

Resumiendo, nuestra política de igualdad de oportunidades se aparta de una concepción muy común de la justicia en política sanitaria. Esta concepción, a menudo denominada igualdad horizontal, establece que las circunstancias de un paciente (como por ejemplo su raza o ingresos) no debieran afectar a las decisiones que se tomen sobre su tratamiento, y en particular, a la cantidad que se invertirá en él. Pero, por el contrario, nucstra política de igualdad de oportunidades invertiría diferentes cantidades por tipo en el tratamiento para compensar a algunos de ellos por la baja esperanza de vida que de otro modo tendrían, sin responsabilidad alguna por su parte. En la figura 1 vemos que hay una tremenda diferencia entre nuestra política y la política de «igualdad horizontal» respecto a la igualación de la esperanza de vida.

¿Cómo debiera aplicarse nuestra política de igualdad de oportunidades? Propondría, a estos efectos, la creación de un seguro sanitario público que solicitase a los hospitales informes tanto sobre el número de casos de una enfermedad tratados, como sobre su distribución entre tipos. El seguro com- 
pensaría entonces a los hospitales pagándoles una cantidad por tratamiento de acuerdo con la asignación de fondos indicada por nuestra política.

\section{IV}

Déjenme exponerles a continuación cómo Julian Betts, un especialista en economía del trabajo del Departamento de Economía de la USCD, y yo mismo hemos aplicado esta teoría para calcular qué política presupuestaria educativa sería actualmente necesaria en los Estados Unidos para igualar las oportunidades de adquirir la misma capacidad de ganarse la vida entre negros y entre blancos. Los cálculos que expondré no intentan igualar oportunidades en general entre niños en circunstancias diferentes: en este cálculo consideramos los efectos de una sola circunstancia, la raza, en su futura capacidad de ganarse la vida. Debo añadir que actualmente estamos elaborando un cálculo más preciso, en el que emplearemos como circunstancia relevante el status socioeconómico de la familia del niño, además de la raza.

Para aplicar la teoría, necesitamos una medida del esfuerzo, y tomaremos como tal la anteriormente propuesta; por ejemplo, el número de cursos escolares a los que el individuo ha asistido. Se podrian emplear, por supuesto, medidas más adecuadas de esfuerzo, pero baste ésta para comenzar. El instrumento de nuestra política son las inversiones educativas en los niños de los dos tipos, negros y blancos, y nuestro propósito es calcular cómo debieran distribuirse tales inversiones de modo que, para cualquier nivel de esfucrzo - es decir, cualquier centil de la distribución de esfucrzo de cada niño blanco o negro-, las ganancias esperadas en un futuro se acerquen tanto como sea posible a la igualdad. Los datos que necesitamos para llevar a cabo el cálculo son los ingresos de un amplio grupo de negros y blancos de, digamos, treinta años de edad, considerados como función de las inversiones educativas per cápita en las escuelas a las que fueron en su juventud, y el número de cursos a los que asistieron (por ejemplo, su esfuerzo). Afortunadamente, en los Estados Unidos disponemos de series temporales de donde podemos extraer estos datos. Puesto que los presupuestos educativos han sido tan dispares en los distintos distritos escolares del país, tenemos un buen experimento natural mediante el cual estimar la capacidad de ganarse la vida en un futuro como respuesta a diferentes inversiones educativas.

Betts y yo calculamos que, para igualar las oportunidades de ganarse la vida en un futuro entre varones blancos y negros, tendríamos que gastar tres veces más en un estudiante negro que en uno blanco. Hay algunas razones, relativas a la calidad de los datos y a la medida del esfuerzo, para no confiar demasiado en esta cifra, pero me parece firme la conclusión de que debiéramos invertir bastante más en un estudiante negro que en uno blanco para igualar sus oportunidades. Por supuesto, la categoría «negro» es aquí una aproximación imperfecta a diversas circunstancias tales como un status socioeconómico bajo, o 
incluso un tratamiento discriminatorio en el mercado laboral. Como decía antes, ahora estamos considerando otras circunstancias adicionales además de la raza, que por sí sola es una categoría demasiado restrictiva para nuestros propósitos.

(Conviene hacer una pequeña digresión. Si los negros constituyen el 15 por 100 de la población, asignarles tres veces los recursos per cápita que reciben los blancos equivale a disminuir en un 23 por 100 lo que éstos recibirían respecto a una política de igual gasto per cápita. Con todo, el coste que les supondría a los blancos aplicar una política de igualdad de oportunidades educativa en Sudálrica sería enorme, pues allí sólo representan un 15 por 100 de la población.)

¿Cómo aplicaría tal política? No propugnaría un sistema de recibos en el que cada estudiante negro recibiese un bono que valiese tres veces más que el asignado al estudiante blanco. Defendería, en cambio, la distribución de los fondos educativos entre las escuelas de acuerdo con la proporción de estudiantes que acogen de cada uno de los tipos. Por tanto, las escuelas que turiesen un 90 por 100 de alumnos negros recibirían fondos en una cantidad de algo menor que el triple de la tasa per cápita de las escuelas con un 90 por 100 de alumnos blancos. Dentro de la escuela, no diferenciaría los gastos según la raza, puesto que ello podría suponer la segregación por aulas y, considerando la imposibilidad de un tratamiento «igual pero separado», pondría en cuestión la calidad de la enseñanza que recibiese la minoría blanca. Cabría suponer que tal política podría fomentar una saludable integración escolar: los tipos más favorecidos tendrían un incentivo para acudir a las escuelas pobladas mayoritariamente por tipos desfavorecidos, puesto que éstas tendrían mayores recursos. Por consiguiente, la asignación de presupuestos educativos tendría que ser recalculada bastante a menudo.

\section{$\mathrm{V}$}

Me ocuparé, por último, del alcance de nuestra política de igualdad de oportunidades.

¿Debieran ser admitidos en equipos profesionales de baloncesto, aplicando el principio de igualdad de oportunidades, un cierto número de jugadores bajitos? Ser bajito es, después de todo, una circunstancia independiente de nuestra voluntad. ¿Dcbicra concederse el título de cirujano a aquellos individuos que suspendan los correspondientes cursos, si se hubiesen csforzado mucho y proviniesen de entornos desfavorecidos? De aplicarse el principio de igualdad de oportunidades, la respuesta sería en ambos casos afïrmativa. Pero no defendería su aplicación en ellos. ¿Cuál es entonces su alcance?

El principio de igualdad de oportunidades considera como objetivo sólo la ventaja resultante (educación, ingresos, empleos), mientras que el principio de no discriminación o de mérito que mencionaba al principio considera no solamente la existencia de un cierto grado de equidad entre quienes compiten, sino también el bienestar de quienes vayan a consumir lo que aquéllos pro- 
duzcan. Por tanto, los jugadores de baloncesto producirán un jucgo consumido por los espectadores y los cirujanos producirán extirpaciones de apéndice consumidas por sus pacientes. Si aplicamos el principio de igualdad de oportunidades a la titulación de cirujanos, concedemos mayor peso a la satisfacción de las aspiraciones de los candidatos. Si aplicamos el principio de no discriminación, concedemos mayor peso a la realización de la vida de los pacientes. En general, uno debe, por supuesto, atender a la ventaja que obtendrán aquellos que aspiran a un puesto y a la de aquellos a quienes servirán en él. Al restringir el dominio de aplicación y cl alcance de las políticas de igualdad de oportunidades se atiende al bienestar de estos últimos.

Debo decir que no creo que podamos decidir definitivamente el alcance adecuado del principio de igualdad de oportunidades sin adoptar una teoría de la justicia distributiva para la comunidad en cuestión. Hasta ahora, mi propósito ha sido describir en qué consistiría la igualdad de oportunidades una vez adoptadas tres decisiones: si debemos o no aplicar cl principio de igualdad de oportunidades a la situación en cuestión (alcance), si las circunstancias definitorias del tipo han sido determinadas (un aspecto del dominio de aplicación), y si se ha establecido la cuantía de los recursos que la sociedad dedicaría a igualar las oportunidades en el caso en cuestión (otro aspecto del dominio de aplicación). Establecer cuál debiera ser esa cuantía requiere una teoría de la justicia distributiva para la comunidad en su conjunto, puesto que la sociedad debe equilibrar cl consumo de la actual generación de adultos con el nivel educativo de sus niños y, por tanto, el grado de realización personal de los que, en un futuro, se convertirán en adultos.

He indicado que podemos ajustar el grado en el que las oportunidades se igualan ajustando la cantidad de recursos dedicados a ello. Otro modo de ajustarlo es restringir el número de circunstancias consideradas. Volvamos a considerar el ejemplo de la educación, donde apuntaba que el Cl podía ser una de cllas. Incluir el CI exigiría, de aplicarse una política de igualdad de oportunidades, invertir cantidades significativas de recursos en niños con un CI bajo y, correlativamente, reducir los recursos invertidos en niños con un CI alto, en el intento de incrementar la capacidad de ganarse un salario de aquéllos al nivel de los niños con un CI más alto. Esto podría suponer una pérdida sustancial en los logros totales de la sociedad en el pcríodo siguiente, cuando estos niños se conviertan en adultos y se unan a la fuerza laboral - supongo aquí que el salario de un obrero es una medida adecuada del valor social del producto de su trabajo-. Está claro que este coste social, en forma de disminución del pastel que consumirá la sociedad, se podría reducir eliminando el CI del conjunto de circunstancias. Esto limitaría el ámbito en el que se aplicaría el principio de igualdad de oportunidades: la decisión supone nivelar el terreno de juego sólo parcialmente, y no por completo. Aquí el principio general sería que otros valores distintos de la igualdad de oportunidades, tales como las dimensiones y calidad del pastel que consumirá la sociedad, pueden restringir 
el dominio en el cual igualaríamos las oportunidades. Este principio a menudo se denomina principio de balance o intercambio entre la igualdad y la eficiencia, término que no me gusta puesto que no debiera tenerse por equivalente la eficiencia social con el tamaño del pastel que se consumirá.

Los demócratas, normalmente preocupados por la igualdad, defenderán, en general, la inclusión de muchas características del entorno de una persona en la lista de circunstancias, y los republicanos, preocupados de ordinario por el tamaño del pastel, defenderán la inclusión de muy pocas características en ella.

Volvamos de nuevo a la cuestión del alcance adecuado de una política de igualdad de oportunidades. Como anteriormente decía, mi propósito es pluralista, en el sentido de que no deseo defender una teoría particular de la justicia distributiva, sino describir lo que, a mi entender, implica la igualdad de oportunidades, de modo que los defensores de una u otra teoría de la justicia puedan aplicarlo en los casos que su teoría prescriba. Considerando lo dicho anteriormente, no puedo prescribir, en rigor, cuál debiera ser el alcance de nuestra política. De todos modos, propondré una regla prudencial para delimitar los dominios del principio de igualdad de oportunidades y el de no discriminación, que pienso que es políticamente realista en las sociedades contemporáneas.

Propongo que el principio de igualdad de oportunidades se aplique donde la ventaja en cuestión consista en la adquisición de una cualificación necesaria para competir por un puesto (un trabajo), y que se aplique solamente el principio de no discriminación llegados a la selección laboral.

Permitanme desarrollarlo. Tener estudios de medicina es necesario para optar a ciertos puestos. Defiendo la aplicación de una política de igualdad de oportunidades en cl proceso de admisión en las Facultades de Medicina. Pero convertirse en un cirujano requiere competir después por tal puesto: aplicaría el principio de no discriminación a la concesión del título o a la contratación de cirujanos. Aquellos individuos desfavorecidos que, pese a su esfuerzo, no superasen los cursos correspondientes no obtendrían su título, de aplicarse esta regla, ni tampoco ningún hospital se vería en la obligación de contratarlos.

De acuerdo con esta restricción, no aplicaría el principio de igualdad de oportunidades a la contratación de jugadores profesionales de baloncesto, pero sí a su selección en Institutos e incluso en la Universidad: pues estos equipos de aficionados en parte forman a los individuos para competir por puestos, tanto de jugadores profesionales como de entrenadores u otros empleos relacionados con el deportc. Considero prudencial mi propuesta: podría defenderse que la función principal de los equipos de aficionados no es entrenar a sus jugadores, sino divertir al público y que la diversión se consigue seleccionando a los mejores jugadores. Una teoría común de la justicia sería necesaria para resolver esta cuestión.

Hay dos objeciones generales que pienso pueden dirigirse contra mi propuesta. La «objeción de derechas» sería que mi propuesta concede demasiado 
alcance al principio de igualdad de oportunidades y no lo suficiente al principio de no discriminación, y la objeción de izquierdas sería que concede demasiado alcance al principio de no discriminación y no lo suficiente al principio de igualdad de oportunidades. Consideraré ambas objeciones en lo que sigue.

Lo que he denominado objeción de derechas se basa en la idea de que la aplicación del principio de igualdad de oportunidades engendra ineficiencia social. Pone en cuestión el intento de distinguir la formación necesaria para competir por un puesto, y la competencia misma. Si se efectúa una gran inversión en educar a individuos de un medio desfavorecido, tendremos correlativamente menos dinero para la educación de los individuos más inteligentes de los medios más favorecidos $y$, por consiguiente, dispondremos de un menor número de personas capaces de hacerse cargo de aquellos puestos que exigen un mayor nivel de inteligencia y cualificación. Aplicar el principio de igualdad de oportunidades en el proceso de admisión en las Facultades de Medicina conduciría a obtener un menor número de aprobados en los exámenes. Si la sociedad necesita un número fijo de cirujanos, la aplicación del principio de igualdad de oportunidades conduciría a la devaluación de los criterios de concesión del título, y a la consecuente disminución de calidad de la cirugía. En realidad, la aplicación del principio de igualdad de oportunidades en cualquier nivel educativo causaría un despilfarro de recursos, que a su vez provocaría la disminución del número de individuos inteligentes y cualificados que la economía necesita para crecer y la sociedad para producir una cesta de bienes y servicios de calidad. La sociedad habrá cumplido con su obligación de igualar las oportunidades si, a través de la educación secundaria, destina a todo individuo igual cantidad de recursos educativos. De ahí en adelante, la competencia por un puesto en la educación supcrior se debe regir por el principio de no discriminación.

La objeción de izquierdas consiste en que la sociedad les debe más a los individuos desfavorecidos que lo que se les asignaría con mi distinción entre estas dos situaciones. Considérese el caso de los cirujanos. Es tan importante que los tipos más desfavorecidos cuenten con representantes en la profesión que dcbicran establecerse criterios más flexibles para concederles el título. Pues solamente al contarse entre los cirujanos individuos de estos tipos se crearán entre sus micmbros más jóvenes aspiraciones que les impulsen a prepararse para estudiar medicina (el efecto señalado en el modelo de rol). Desde luego que con ello se reduciría la calidad de la atención quirúrgica que algunos pacientes recibirían, pero éstos debieran considerar tal reducción como la devolución parcial de una deuda contraída por la sociedad con estos tipos desfavorecidos, recordando que, por definición, lo son a causa de circunstancias de las que la sociedad dice no considerarles responsables.

Decía anteriormente que mi propuesta sobre el alcance del principio de igualdad de oportunidades está formulada de acuerdo con lo que, a mi juicio, defenderían un amplio número de ciudadanos de muchas democracias indus- 
triales avanzadas. Pienso, concretamente, que entenderían, en primer lugar, que el coste social de cubrir unos puestos con individuos relativamente incompetentes sería mayor que el beneficio que se obtendría con ello y, en segundo lugar, que los beneficios que reciben de la educación los individuos desfavorccidos y lo que con ello obtiene la sociedad son mayores quc el coste social inmediato de las oportunidades perdidas por aplicar en tales casos una política de igualdad de oportunidades.

Mi evaluación de este criterio de la ciudadanía se basa, en parte, en la experiencia estadounidense con la política de discriminación positiva: más precisamente, en un aspecto concreto de esta experiencia. La política de discriminación positiva, como todo el mundo sabe, está siendo objeto de ataques en los Estados Unidos, tanto por su aplicación en la selección laboral, como en los procesos de admisión en la Universidad y en programas de educación superior. Hay, en cualquier caso, una importante diferencia en la naturaleza del ataque a la discriminación positiva cn estos dos casos. Respecto a la competencia por un emplco, el ataque consiste en abogar por que el candidato más preparado obtenga el puesto, pero respecto a la admisión en la Universidad sc sostiene que la raza no es una buena medida de la desventaja. Incluso Ward Connerly, el Canciller de la Universidad de California que encabezó la exitosa campaña para acabar con las políticas de discriminación positiva en el sistema de admisión en su Universidad, declara apoyar la admisión preferente de estudiantes de un status socioeconómico bajo. Por tanto, el ataque a la política de igualdad de oportunidades en la admisión en la Universidad se dirige no a la aplicación del principio, sino a la determinación del conjunto de circunstancias.

En cambio, la crítica de la discriminación positiva en la selección laboral se dirige al principio mismo, argumentándose, en la terminología que cmpleamos aquí, que el principio de no discriminación es el que ha de aplicarse. Una vez provistos de los criterios sobre la igualdad de oportunidades que acabamos de ofrecer aquí, es evidente que estas dos críticas de las políticas de discriminación positiva son muy diferentes: en la medida en que se refieren a la educación, no se pone en cuestión el principio de nivelación del campo de jucgo, mientras que sí se pone en cuestión en el caso en los procesos de selección laboral.

He ilustrado el algoritmo de igualdad de oportunidades con ejemplos de asignación de presupuestos educativos y sanitarios. Ambas aplicaciones se incluyen en lo que considero la jurisdicción propia de las políticas de nivelación del terreno de juego. En cada caso deben tomarse cuatro decisiones para poder calcular una política de igualdad de oportunidades: cuál cs el objetivo o resultado de la política (ingreso, esperanza de una vida de calidad), cuáles son las cir- 
cunstancias relevantes, cuál la medida de esfuerzo pertinente, y cuál el instrumento de la política (asignación de inversiones educativas, seguros, o subvención de los tratamientos médicos). En cada una de estas decisiones hay opciones, y la clegida dependerá no solamente de consideraciones filosóficas y políticas, sino también de la disponibilidad de los datos necesarios. 